\title{
Occupant satisfaction in LEED and non-LEED certified buildings
}

\author{
Sergio Altomonte ${ }^{\mathrm{a}}$, Stefano Schiavon ${ }^{\mathrm{b} *}$
}

\author{
${ }^{a}$ Department of Architecture and Built Environment, University of Nottingham, University Park, Nottingham, \\ NG7 2RD, UK \\ ${ }^{\mathrm{b}}$ Center for the Built Environment, University of California, 388 Wurster Hall, Berkeley, CA 94720-1839, USA \\ * Corresponding author: stefanoschiavon@ berkeley.edu
}

Received 29 March 2013; Received in revised form 26 May 2013; Accepted 6 June 2013

\begin{abstract}
Occupant satisfaction with indoor environmental quality (IEQ) in office buildings has been positively correlated to self-estimated job performance and, potentially, to overall company productivity. LEED is a voluntary, consensus-based, market-driven program that provides third-party certification of green buildings, contributing to promote sustainability into the mainstream of building design and construction. From the literature, however, it is unclear the extent to which LEED certification also improves occupant satisfaction with IEQ. The aim of this paper is to study if LEED certified buildings lead to a higher, equal or lower satisfaction with indoor environmental quality than non-LEED rated buildings. Occupant satisfaction has been evaluated on a subset of the Center for the Built Environment Occupant Indoor Environmental Quality Survey database featuring 144 buildings (65 LEED certified) and 21,477 individual occupant responses (10,129 in LEED buildings). Differently from previous studies of the CBE database, the results show that occupants of LEED certified buildings have equal satisfaction with the building overall and with the workspace than occupants of non-LEED rated buildings. The difference in mean satisfaction scores between LEED and non-LEED buildings for other 15 IEQ parameters investigated is always lower than $6 \%$ with a negligible effect size. Therefore, it can be concluded that there is not a significant influence of LEED certification on occupant satisfaction with indoor environmental quality, although the analysis of mean votes of satisfaction reveals that occupants of LEED buildings tend to be slightly more satisfied with air quality, and slightly more dissatisfied with amount of light.
\end{abstract}

Altomonte, S. Schiavon, S. 2013. Occupant satisfaction in LEED and non-LEED certified buildings. Building and Environment. 68, 66-76 


\section{HIGHLIGHTS}

- $\quad$ Occupant satisfaction with IEQ was analyzed in 65 LEED and 79 non-LEED buildings

- $\quad$ Results differ from literature also due to larger sample and new statistical tests

- $\quad$ The difference in satisfaction with the building and the workspace was negligible

- Mean satisfaction vote with indoor air quality was slightly higher in LEED offices

- Mean satisfaction vote with amount of light was slightly lower in LEED offices

\section{KEYWORDS}

Leadership in Energy and Environmental Design (LEED), Occupant Satisfaction, Survey, PostOccupancy Evaluation, Indoor Environmental Quality, Rating Tools

\section{INTRODUCTION}

The satisfaction of occupants in office buildings is affected by thermal, acoustic and visual parameters, by air quality, and by other features of the workspace - and of the building - such as view, furniture layout, amount of privacy, cleanliness and level of personal control over the internal environment [1]. The satisfaction of occupants has been correlated to the self-estimated job performance of office workers [2], this having an effect on frequency and duration of absenteeism and intention to quit work and, potentially, to overall company productivity [3]. Therefore, occupant satisfaction is an important factor in the design, operation and management of buildings.

LEED (Leadership in Energy and Environmental Design) is a voluntary, consensus-based, market-driven program that provides third-party certification of green buildings [4]. LEED is the most popular building rating tool in the United States, and its market share is continuing to grow, both in the US and internationally [5]. Irrespective of the LEED product used for the certification, there is a general perception amongst the actors of the building industry that LEED - as well as other rating tools such as BREEAM in UK, Green Mark in Singapore, Green Star in Australia, etc. - has effectively contributed to bring sustainability into the mainstream of building design and construction [6,7]. However, less clear from the literature is the extent to which the use of a rating tool can actually improve indoor environmental quality and workplace satisfaction for the occupants of the certified buildings. In this context, it should be mentioned that the evidence of the energy savings effectively facilitated by rating tools has also been analyzed by studies that have looked at actual energy use of LEED certified buildings versus a comparable dataset of existing commercial buildings in the US [8,9]. The outcomes concluded that it is complex to provide a comprehensive calculation of the effective reduction in primary (source) energy use in commercial buildings certified by LEED compared to not-rated office spaces.

In the following paragraphs, this paper will introduce the LEED program, the Center for the Built Environment (CBE) Occupant Indoor Environmental Quality Survey, and will analyze the results of previous studies focusing on the relationship between indoor environmental quality, LEED/green rating and occupant satisfaction.

\subsection{The LEED program}

With the inception of the first LEED Pilot Project Program (LEED v1.0) in 1998 - and the launch of the LEED Green Building Rating System Version 2.0 (thereafter known as LEED for New Construction) in 2000 [10] - the United States Green Building Council (USGBC) has created a framework for rating new and existing buildings that encompasses to date several thousand certifications awarded across 135 countries. In February 2013, the USGBC indicated as 15,183 the number of commercial buildings having received LEED certification worldwide [11]. The USGBC defines as "green buildings" those that "significantly reduce or eliminate negative impacts on the environment and the occupants" [4]. Today, LEED consists of nine products, covering the design, construction and operation of: New Constructions \& Major Renovations; Existing Buildings: Operation \& Maintenance; Commercial Interiors; Core \& Shell Development; Retail; Schools; Homes; Neighborhood Development; and, Healthcare. This paper only analyzes buildings certified under the first three LEED products.

LEED for New Construction (LEED-NC) v1.0 was launched in 2000 as the first LEED rating scheme geared towards the construction of new commercial buildings and major renovations [12]. LEED for Existing Buildings (LEED-EB) was released in 2002 to promote sustainable practices and the reduction of environmental impacts by addressing aspects of ongoing existing building operations. [13]. LEED for Commercial Interiors (LEED-CI) was launched in 2004 to certify interior tenant spaces, i.e. targeting users that lease their space or do not occupy the entire building.[14]. Following their initial releases, several versions of the various LEED products have been launched, up to the latest version 4 that was at the stage of beta testing when writing this paper [15].

All LEED products encompass five common credit categories: a) Sustainable sites; b) Water efficiency; c) Energy \& atmosphere; d) Materials \& resources; and, e) Indoor Environmental Quality (IEQ). 
In the current version 2009 of the LEED products considered, credits obtainable within the IEQ category (15 credits under LEED-NC and LEED-EB, and 17 under LEED-CI) are either required or voluntary. In LEED$\mathrm{NC}$, the two mandatory IEQ credits address minimum indoor air quality performance and tobacco smoke control, while voluntary credits encompass areas such as ventilation, IAQ management plan, low-emitting materials, controllability of systems, visual and thermal comfort. In LEED-EB, three credits are required respectively for IAQ performance, tobacco smoke control and green cleaning policy, while other voluntary areas of certification include IAQ management practices, occupant surveys, controllability of lighting systems, thermal comfort monitoring, daylight and views, and green cleaning. In LEED-CI, the IEQ credit distribution is identical to LEED$\mathrm{NC}$, with the addition of one voluntary credit for low-emitting materials (systems furniture and seating) and one for daylight and views. For all the products of LEED v2009, certification is awarded according to the following scale: Certified (40-49 points), Silver (50-59 points), Gold (60-79 points), Platinum (80 points and above) [11].

\subsection{The CBE Occupant Indoor Environmental Quality Survey}

To investigate occupant satisfaction and its correlation with indoor environmental quality parameters and building features, the Center for the Built Environment (CBE) at the University of California Berkeley has developed a web-based survey and online reporting tool [16]. The resulting database provides a unique opportunity to investigate the factors that drive satisfaction in the workplace from the perspective of the occupants.

The CBE survey grew out of earlier thermal comfort studies conducted at CBE, based on an established in-depth pre-testing method called 'cognitive interviewing', and used by the Survey Research Center at UC Berkeley to assess how well respondents were able to comprehend and accurately report answers to questions [17].

The survey is currently composed of core and optional modules, which can be added basing on specific buildings' characteristics or due to interest in particular features. The core survey appraises the satisfaction of occupants under the categories described in Table 1.

Table 1 Categories included in the CBE Occupant Indoor Environmental Quality Survey

\begin{tabular}{ll}
\hline Office Layout & $\begin{array}{l}\text { Amount of space available for individual work and storage } \\
\text { Level of visual privacy } \\
\text { Ease of interaction with co-workers }\end{array}$ \\
\hline Office Furnishings & $\begin{array}{l}\text { Comfort of office furnishings (chair, desk, computer, equipment, etc.) } \\
\text { Ability to adjust furniture to meet your needs } \\
\text { Colors and textures of flooring, furniture and surface finishes }\end{array}$ \\
\hline Thermal Comfort & Temperature in your workspace \\
\hline Air Quality & Air quality in your workspace (i.e. stuffy/stale air, air cleanliness, odors) \\
\hline Lighting & $\begin{array}{l}\text { Amount of light in vour workspace } \\
\text { Visual comfort of the lighting (e.g., glare, reflections, contrast) }\end{array}$ \\
\hline Acoustic Quality & $\begin{array}{l}\text { Noise level in your workspace } \\
\text { Sound privacy in your workspace (ability to have conversations without neighbors } \\
\text { overhearing and vice versa) }\end{array}$ \\
\hline Cleanliness and & $\begin{array}{l}\text { General cleanliness of the overall building } \\
\text { General maintenance of the building }\end{array}$ \\
\hline General Comments & $\begin{array}{l}\text { Your personal workspace } \\
\text { Building overall }\end{array}$ \\
\hline
\end{tabular}

These categories are clearly not exhaustive to fully describe the satisfaction and comfort of building users, however, they are all pertinent. The survey uses 7-point ordered scale questions to evaluate occupant satisfaction with indoor environmental quality parameters, workspace and building features, ranging from 'very satisfied' (+3) to 'very dissatisfied' (-3), with a neutral midpoint (0) [1]. The survey also collects information about occupants (e.g., gender, age group, type of work, office type, distance of workspace from the window, period of time since starting work in the current building and workstation, weekly working hours, etc.) and about the building characteristics (e.g., year of construction or renovation, location, size, number of floors and occupants, shading devices and control, LEED certification, energy use, cost of construction, etc.). This latter information is provided by the building facility manager - or the survey administrator - for each building where the survey is administered. The full database currently includes in excess of 600 buildings (featuring commercial 
buildings, healthcare facilities, laboratories, educational buildings, libraries, etc.) and 65,000 individual occupant responses obtained over a period of more than ten years across the United States, Canada, Europe and Australia.

The CBE survey has already been applied in various research scenarios, providing the possibility of evaluating the effectiveness of a design intervention, or informing the development of design guidelines for new buildings. The survey can also be used as a benchmarking tool to compare a building's performance against other buildings from the point of view of the occupants, and can also represent a valuable diagnostic instrument to recognize specific problems and their sources [18].

\subsection{Indoor environmental quality, LEED rating and occupant satisfaction}

A vast literature of studies has looked at the relationship between IEQ and occupant satisfaction in commercial office buildings. The following investigations were selected since they analyze more directly the connection between green rating tools (such as LEED) and users' satisfaction, health and productivity.

Data from the CBE survey have been utilized in several studies. An early work by Huizenga et al. [17] analyzed and compared the responses obtained in 3 LEED certified buildings against the rest of the CBE database, comprising at the time of the study of 45 buildings in US and Europe. Although based on a very limited sample, these preliminary results showed that green-rated buildings are characterized by higher occupant satisfaction particularly for indoor air quality. A larger sample of 16 LEED rated and 9 self-nominated 'green' buildings (i.e., buildings having received awards for their sustainable credentials) was used by Huizenga et al. [19] to examine occupants' responses in 'sustainable' buildings within the CBE database. The research revealed that green buildings received statistically significant higher votes of satisfaction with the building and the workspace, indoor air quality, cleaning and maintenance, and thermal comfort. However, LEED and self-nominated green buildings did not perform better for lighting and for acoustics. The study did not find a clear relationship between LEED credits and occupant satisfaction with IEQ parameters, therefore suggesting that LEED certification per se may not guarantee a better perception of indoor environmental quality by its occupants. Based on a similar subset of the CBE database, Abbaszadeh et al. [20] analyzed 33,285 responses from 181 buildings, of which 15 had been certified by LEED and 6 had been indicated by their designer/owner as designed or operated in a sustainable way. The results revealed that, on average, occupants of green buildings showed statistically significant higher satisfaction in comparison with the rest of the CBE database in the following areas: office furnishing, thermal comfort, air quality, cleaning and maintenance, workspace, and building overall. Higher mean scores of satisfaction with these parameters were obtained in LEED/green buildings also when including in the comparison only 'non-green' buildings newer than 15 years - and thus chronologically similar to the LEED/green group although in this case these relationships were found to be not statistically significant (with the exception of satisfaction with air quality). The difference between satisfaction votes in LEED/green buildings and the all-age inclusive rest of the database was found to be, on average, small and not statistically significant for: office layout, lighting, and acoustics. An analysis of the same subset of the CBE database was also presented in Lee and Kim [21] and in Lee and Guerin [22], which analyzed the IEQ parameters that mostly affect occupant satisfaction and self-estimated job performance in LEED buildings, and compared the results obtained with non-LEED certified buildings. The studies concluded that LEED certified buildings showed higher occupant satisfaction and perceived job performance with office furnishings, indoor air quality, cleanliness and maintenance. Conversely, lower mean scores of satisfaction were obtained with office layout, lighting, and acoustic quality. Finally, in terms of the influence of subjectively evaluated indoor environmental parameters and building features on occupant satisfaction, Frontczak et al. [1] analyzed the responses from 350 buildings of the CBE database, showing that, in average, building occupants were satisfied with their workspace and the building, and with all the IEQ parameters of the CBE survey. The study also indicated that, amongst all the parameters included in the database, satisfaction with the amount of space available for individual work and storage was the most important factor affecting workspace and overall building satisfaction, followed by noise level and visual privacy.

Although the results of these studies of the CBE survey database provide important advance in the exploration of the relationship between LEED/green certification and occupant satisfaction with the indoor environment, in interpreting their outcomes the following limitations must be taken into account: these investigations were based on a relatively small sample of buildings (particularly in terms of buildings with LEED certification) and, in some cases [21,22], they were only using secondary data (i.e. without consideration and /or verification of building size, year of construction, etc.); the comparisons were made between buildings and not between individual occupants' responses; no selection of the responses available in the CBE database was made so as to compare only those obtained in buildings of similar size and age; the results were based mostly on the analysis of mean and median, without consideration of other statistical measures such as the effect size.

As far as occupants' perception of health and productivity is concerned, Baird et al. [23] studied whether users perceive the performance of green buildings differently from conventional ones. To this aim, a comparison with respect to 44 factors related to operational, environmental, personal control and satisfaction between two sets 
of buildings was performed. The two groups featured, on the one side, 31 'green' commercial or institutional buildings located in 11 countries, and, on the other, 109 buildings chosen within a larger database (although not representative of a random statistical sample). The results indicated that green buildings were perceived by occupants as performing better in terms of operation and satisfaction scores, with significant improvement particularly in perceived productivity. However, modest improvements were found in thermal conditions and lighting, and no significant difference was observed for perception of noise and personal control. Singh et al. [24] investigated the role of improved IEQ in two pre-and post case studies of occupants moving from conventional to LEED certified office buildings. They found that improvements in IEQ contributed to the reduction in occurrence of absenteeism as perceived by the employees, and to the decrease of self-assessed number of hours of work affected by asthma, respiratory allergies, depression and stress. Following the move, employees also reported a perception of enhanced productivity. However, these results may have been biased by the fact that, for the first study, the pre-move survey was conducted 4 to 6 weeks after the move, hence bringing the risk of a recollection bias. Another limitation may have been represented by the fact that pre- and post-move surveys were taken at different times of the year, so asthma and allergy symptoms may have been affected by seasonal factors.

To inform a comparative analysis of conventional and green buildings from the point of view of the users, Leaman et al. [25] performed a post-occupancy evaluation in 22 'green-design intent' and 23 conventional buildings in Australia. The study revealed that most green buildings outperformed conventional ones particularly for occupant satisfaction with 'soft' parameters such as design, needs, image and health. However, due to their relative infancy, the first generation of Australian green buildings showed a wider spectrum of performances and may be underperforming in terms of perception of 'physical' variables (e.g., noise and, in particular, temperature). A further study by Leaman and Bordass [26] in United Kingdom confirmed these results, analyzing and comparing occupants' surveys from 177 buildings half of which had been designed with 'green' aims. The findings indicated a wide spread of scores for green buildings, with improvements particularly in areas such as image and speed of response when comfort thresholds are breached. Green buildings revealed some concerns in terms of operational management, although users showed a tendency to be more tolerant to such deficiencies compared to occupants of conventional buildings. Finally, of particular relevance is the work of Newsham et al. [27], which analyzed 2,545 occupant responses collected simultaneously with physical building measurements (e.g., thermal, air quality, acoustics, and lighting conditions), appraisal of workstations characteristics (e.g., workstation size, ceiling height, window access, shading, electric lighting system, and surface finishes) and energy use data from 24 buildings (12 LEED/green buildings 'twinned' with 12 similar conventional buildings) in Canada and the US. The results indicated that LEED/green buildings exhibited superior environmental performance, with improvements particularly in overall environmental satisfaction, satisfaction with thermal conditions, view to the outside, aesthetic appearance, disturbance from HVAC noise, workplace image, night-time sleep quality, mood, physical symptoms, and number of airborne particulates.

In summary, the researches described here show evidence that occupant satisfaction, health and productivity is generally higher in green buildings compared to conventional ones. In light of these studies, the aim of this paper was set to analyze the responses of the CBE Occupant Indoor Environmental Quality Survey, selecting a larger sample of LEED buildings than those included in the literature available to date. This was to effectively measure up the perception of occupants of commercial office buildings in terms of satisfaction with the building, the workspace, and a wide range of IEQ parameters, and measure it against a comparable set of responses in non-LEED certified buildings. In order to do so, a re-analysis of part the CBE survey database had to be performed so as to select an appropriate dataset of buildings and occupants' responses for the purpose of the proposed analysis.

\section{METHODS}

\subsection{Selection of buildings}

A subset of the CBE Occupant IEQ Survey database has been used for the study presented in this paper. The chosen subset - for consistency, comparability of results, and ease of examination - has been based on the dataset utilized by the mentioned study by Frontczak et al. [1]. We focused on the survey's main core questions.

To identify the buildings and occupants' responses to be included in their evaluation, Frontczak et al. [1] made a selection from the CBE database based on whether: the buildings' purpose was mainly for office-type activities; the buildings featured office-like workstations of varied layouts; and, the survey had a response rate higher than 5\%. The resulting dataset contained 52,980 responses of occupants working in offices, collected in 397 surveys administered in 350 different buildings - mainly governmental, offices occupied by private companies, universities and research centers (to note that in 40 buildings the survey was conducted more than once).

The first stage of the present study consisted in analyzing the available dataset, starting from the localization of the buildings therein included. It was noted that the 350 buildings were distributed across, respectively: Australia (19 buildings, $5.7 \%$ of the dataset), Canada (17 buildings, $4.8 \%$ of the dataset), Europe (17 
buildings, $4.8 \%$ of dataset) and, predominantly, the US (292 buildings, $83.4 \%$ of the dataset). For five buildings included in the dataset, no information was available in terms of their location; therefore, the corresponding individual occupants' responses were excluded from this study.

Upon an initial appraisal of the dataset, it was found that 49 buildings had been flagged by the facility manager or survey administrator as having received (or being in the process of receiving) a LEED certification. This list of 49 LEED buildings was compared with the online USGBC Certified Project Directory [28] to verify and, if necessary, update - the information available. The LEED certification was updated for 28 of the selfdeclared LEED buildings, if: a) the rating was still pending at the time of the survey; or, b) information on the LEED product or version had not been correctly indicated or was absent. Further data for the LEED buildings was also verified (e.g., year of construction/renovation, building size, etc.). It was noticed that 2 of the 49 self-declared LEED buildings were not included in the USGBC Certified Project Directory, since one had received an equivalent certification under a rating scheme other than LEED, whilst the other was only registered with USGBC. The 2 buildings were omitted from the LEED group for the purpose of the present study. Also, 4 other selfreported LEED certified buildings did not figure on the USGBC Certified Project Directory (probably for issues of privacy or confidentiality), but their certification was confirmed by other official documents.

A verification was performed, at this stage, with respect also to the other 296 buildings included in the dataset utilized by Frontzak et al. that had not been indicated as LEED certified by their building/survey administrators. Basing on the USGBC Certified Project Directory, it was found that further 25 buildings of the dataset had effectively received a LEED certification, although such information had not been featured in the building information card. We decided to include in our group of LEED buildings 19 out of these 25 LEED certified buildings, conditional to the certification having been received before or within one year after the date of administration of the CBE survey. The time of one year was considered as a realistic period necessary to complete the process of certification. In fact, the 6 LEED certified buildings that we decided not to include in the LEED group of our dataset had received their certification between 2 and 8 years after the date of the survey, therefore potentially indicating some substantial alterations of the features of the building (these 6 buildings had all received a LEED certification for Existing Buildings: Operations \& Maintenance).

At the conclusion of this appraisal, 66 buildings of the original dataset were included amongst those with LEED certification, as opposed to 279 buildings which were categorized in the non-LEED group. It must be noted that this selection does not exclude that the non-LEED buildings may have received some other certification or 'green' credential by an alternative rating system, or may have some or several high performance features. This possibility is, however, beyond the scope of this study, which focuses exclusively on the satisfaction of occupants in office buildings rated by the LEED program at the time of the survey (or a maximum of one year after it).

A further analysis of the dataset was then performed to confirm the information related to the year of construction, and the eventual year of renovation, and the size of each building of the dataset. Information was again obtained from the USGBC database for the LEED certified buildings and from other sources (e.g., the US General Service Administration building database). Building characteristics were updated for 112 buildings, while no detailed information was found for 50 buildings, which were consequently excluded from the present analysis. This left a dataset populated by 295 buildings in total (66 LEED certified buildings and 229 non-LEED buildings).

In order to guarantee consistency in the data analyzed and perform a coherent comparison of occupant satisfaction in LEED and non-LEED rated buildings, an additional variable was introduced in the selection of the dataset, i.e. the most recent date amongst the year of construction or renovation. Due to the fact that almost all LEED certified buildings included in the CBE database have been built or renovated in the last 15 years, a decision was taken to assume the year 1998 as a baseline for our selection (i.e. the year of the launch of the first LEED Pilot Project Program [10]). In this case, it has been assumed that buildings built or renovated after that date could have been at least informed by some of the principles at the base of LEED or other equivalent rating tool.

The choice of the baseline at the year 1998 allowed to obtain two comparable groups for performing the analysis of this paper; these groups will be from now called respectively "LEED" buildings - indicating buildings having received a minimum of a "certified" rating under one of the three LEED products considered (i.e., Commercial Interiors, New Construction, and Existing Buildings); and "non-LEED" buildings - featuring buildings that have not received a certification under the LEED program. Following the postulation of 1998 as the baseline for inclusion of the buildings in our analysis, one building was excluded from the LEED group, and 149 buildings were excluded from the non-LEED group.

A final verification was also conducted with respect to consistency in the size of the buildings between the LEED and the non-LEED group. Within the non-LEED group, one building was removed since its gross area $\left(177,745 \mathrm{~m}^{2}=1,913,235 \mathrm{gsf}\right)$ largely exceeded the rest of the sample. 


\subsection{Description of the dataset}

Following the selection criteria described in the previous paragraph, the resulting dataset considered for this study is illustrated in the following Table 2 .

Table 2 Description of the dataset used for the analysis of this paper

\begin{tabular}{llll}
\hline Dataset & LEED Buildings & non-LEED Buildings & Total \\
\hline Number of Buildings & 65 & 79 & 144 \\
Number of Occupants' Responses & 10,129 & 11,348 & 21,477 \\
\hline
\end{tabular}

The two groups - LEED and non-LEED - are homogeneous not only in terms of the number of buildings and individual occupants' responses, but also in terms of their year of construction and/or renovation, and their size. In fact, as per the following Table 3, the summary statistics are comparable.

Table 3 Summary statistics

\begin{tabular}{lllll}
\hline Variable & \multicolumn{2}{c}{ Year of construction/renovation } & \multicolumn{2}{c}{ Building size } \\
\hline Value & LEED & non-LEED & LEED & non-LEED \\
1st Quartile & 2002 & 2000 & $6,763 \mathrm{~m}^{2}(72,800 \mathrm{gsf})$ & $15,491 \mathrm{~m}^{2}(166,745 \mathrm{gsf})$ \\
Median & 2004 & 2002 & $26,013 \mathrm{~m}^{2}(280,000 \mathrm{gsf})$ & $26,556 \mathrm{~m}^{2}(285,844 \mathrm{gsf})$ \\
3rd Quartile & 2007 & 2004 & $31,216 \mathrm{~m}^{2}(336,008 \mathrm{gsf})$ & $33,885 \mathrm{~m}^{2}(364,738 \mathrm{gsf})$ \\
\hline
\end{tabular}

As far as LEED buildings are concerned, of the 65 buildings included in the LEED group, 11 have achieved a certification of Platinum (16.9\% of the total number of LEED buildings), 27 have been certified as Gold (41.5\%), 13 have a certification of Silver (20\%) and 14 have a rating of Certified (21.6\%).

Table 4 below illustrates the distribution of occupants' responses in our dataset basing on the product, level of certification, and version of the rating tool that each building of the LEED group has been certified with. This distribution is also compared with the classification of all the commercial office buildings that have received to date a LEED certification under LEED-NC, LEED-EB and LEED-CI according to the version of LEED product used, based on information provided to the authors by the USGBC (last updated in February 2013).

Table 4 Distribution of occupants' responses in our dataset and comparison with all LEED certified commercial offices

\begin{tabular}{|c|c|c|c|c|}
\hline \multicolumn{5}{|c|}{ Dataset (number of responses) } \\
\hline LEED Rating & LEED-NC & LEED-EB & LEED-Cl & Total (responses) \\
\hline Platinum & $505(6 \%)$ & $221(29 \%)$ & $275(16 \%)$ & $1,001(10 \%)$ \\
\hline Gold & $5,638(74 \%)$ & $549(71 \%)$ & $255(15 \%)$ & $6,442(64 \%)$ \\
\hline Silver & $853(11 \%)$ & - & $382(23 \%)$ & $1,235(12 \%)$ \\
\hline Certified & $667(9 \%)$ & - & $784(46 \%)$ & $1,451(14 \%)$ \\
\hline Total & $7,663(76 \%)$ & $770(7 \%)$ & $1,696(17 \%)$ & 10,129 \\
\hline LEED Version & LEED-NC & LEED-EB & LEED-Cl & Total (responses) \\
\hline 1 & $303(4 \%)$ & $76(10 \%)$ & $527(31 \%)$ & $906(9 \%)$ \\
\hline 2.0 & $3,693(48 \%)$ & $221(29 \%)$ & $1,169(69 \%)$ & $5,083(50 \%)$ \\
\hline 2.1 & $3,371(44 \%)$ & - & - & $3,371(33 \%)$ \\
\hline 2.2 & $296(4 \%)$ & $473(61 \%)$ & - & $769(8 \%)$ \\
\hline Total & $7,663(76 \%)$ & $770(7 \%)$ & $1,696(17 \%)$ & 10,129 \\
\hline \multicolumn{5}{|c|}{ USGBC LEED Certified Commercial Offices (number of buildings) } \\
\hline LEED Version & LEED-NC & LEED-EB & LEED-Cl & Total (buildings) \\
\hline 1 & $2(0 \%)$ & $17(1 \%)$ & $46(2 \%)$ & $65(1 \%)$ \\
\hline 2.0 & $93(4 \%)$ & $187(13 \%)$ & $1,368(57 \%)$ & $1,648(26 \%)$ \\
\hline 2.1 & $396(16 \%)$ & - & - & $396(6 \%)$ \\
\hline 2.2 & $1,617(66 \%)$ & $722(48 \%)$ & - & $2,339(37 \%)$ \\
\hline 2009 & $326(13 \%)$ & $565(38 \%)$ & $978(41 \%)$ & $1,869(30 \%)$ \\
\hline Total & $2,434(39 \%)$ & $1,491(24 \%)$ & $2,392(38 \%)$ & 6,317 \\
\hline
\end{tabular}

Table 5 below presents the total number and distribution of individual occupants' responses in LEED and non-LEED certified buildings based on the consideration of various 'non-environmental' factors, such as spatial layout, features of the workspace and of the building, occupants' characteristics and working activities. The use of 
the term 'non-environmental' derives from a literature survey reported in [29] to indicate "factors, unrelated to environmental quality, that influence whether indoor environments are considered to be comfortable or not".

Table 5 Distribution of occupants' responses in LEED and non-LEED buildings based on 'non-environmental' factors

\begin{tabular}{|c|c|c|c|}
\hline Non Environmental Factors & Number of Oc & Responses & \\
\hline Spatial Layout & LEED & non-LEED & Total \\
\hline Private Office & 1,738 & 2,413 & \\
\hline Shared Office & 340 & 635 & $5,126(24 \%)$ \\
\hline Subtotal (Enclosed Offices) & $2,078(21 \%)$ & $3,048(27 \%)$ & \\
\hline Cubicles with high partitions* & 5,177 & 4,285 & \\
\hline Cubicles with low partitions & 2,425 & 3,043 & \\
\hline Other (Bullpen) ${ }^{\star *}$ & 449 & 972 & $10,351(16 \%)$ \\
\hline Subtotal (Open Spaces) & $8,051(79 \%)$ & $8,300(73 \%)$ & \\
\hline Total & 10,129 & 11,348 & 21,477 \\
\hline Distance from Window & LEED & non-LEED & Total \\
\hline Within 4.6 meters ( 15 feet) & $6,661(66 \%)$ & $7,671(69 \%)$ & $14,332(67 \%)$ \\
\hline Further than 4.6 meters ( 15 feet) & $3,427(34 \%)$ & $3,491(31 \%)$ & $6,918(33 \%)$ \\
\hline Total & 10,088 & 11,162 & 21,250 \\
\hline Building Size & LEED & Non-LEED & Total \\
\hline Small (less than $4,645 \mathrm{~m}^{2}$ or $50,000 \mathrm{gsf}$ ) & $1,150(16 \%)$ & $634(6 \%)$ & $1,784(11 \%)$ \\
\hline Medium (between 4,645 and 18,580 m²) & $1,733(24 \%)$ & $2,882(30 \%)$ & $4,615(27 \%)$ \\
\hline Large (higher than $18,580 \mathrm{~m}^{2}$ or 200,000 gsf) & $4,283(60 \%)$ & $6,240(64 \%)$ & $10,523(62 \%)$ \\
\hline Total & 7,166 & 9,756 & 16,922 \\
\hline Gender & LEED & non-LEED & Total \\
\hline Female & $2,517(56 \%)$ & $6,206(57 \%)$ & $8,723(57 \%)$ \\
\hline Male & $2,011(44 \%)$ & $4,645(43 \%)$ & $6,656(43 \%)$ \\
\hline Total & 4,528 & 10,851 & 15,379 \\
\hline Age & LEED & non-LEED & Total \\
\hline 30 or under & $929(21 \%)$ & $1,019(17 \%)$ & $1,948(19 \%)$ \\
\hline $31-50$ & $2,326(51 \%)$ & $3,145(54 \%)$ & $5,471(53 \%)$ \\
\hline Over 50 & $1,264(28 \%)$ & $1,669(29 \%)$ & $2,933(28 \%)$ \\
\hline Total & 4,519 & 5,833 & 10,352 \\
\hline Type of Work & LEED & non-LEED & Total \\
\hline Administrative & $829(17 \%)$ & $568(22 \%)$ & $1,397(19 \%)$ \\
\hline Technical & $889(19 \%)$ & $468(18 \%)$ & $1,357(19 \%)$ \\
\hline Professional & $2,024(43 \%)$ & $973(37 \%)$ & $2,997(41 \%)$ \\
\hline Managerial/Supervisory & $641(14 \%)$ & $437(17 \%)$ & $1,078(15 \%)$ \\
\hline Other & $339(7 \%)$ & $155(6 \%)$ & $494(6 \%)$ \\
\hline Total & 4,722 & 2,601 & 7,323 \\
\hline Time at Workspace & LEED & non-LEED & Total \\
\hline 4-6 months & $339(9 \%)$ & $200(9 \%)$ & $539(9 \%)$ \\
\hline $7-12$ months & $865(24 \%)$ & $460(22 \%)$ & $1,325(23 \%)$ \\
\hline More than 1 year & $2,410(67 \%)$ & $1,449(69 \%)$ & $3,859(68 \%)$ \\
\hline Total & 3,614 & 2,109 & 5,723 \\
\hline Weekly Working Hours & LEED & non-LEED & Total \\
\hline 10 or less & $272(4 \%)$ & $403(4 \%)$ & $675(4 \%)$ \\
\hline $11-30$ & $1,406(18 \%)$ & $1,954(18 \%)$ & $3,360(18 \%)$ \\
\hline More than 30 & $6,106(78 \%)$ & $8,274(78 \%)$ & $14,380(78 \%)$ \\
\hline Total & 7,784 & 10,631 & 18,415 \\
\hline
\end{tabular}

*Higher than 1.5 meters

**The Other category includes open layouts such as: workspace in open office with two partitions; cubicles with partitions of different heights; group work area; open plan with limited partitions; open workspace with no partitions

From Table 5, it is clear that the two groups of buildings selected for our analysis - LEED and non-LEED - are comparable also based on consideration of 'non-environmental' factors, with only relatively minor 
differences. In average, in both groups the majority of users (76\%) indicated to occupy a workspace arranged in an open spatial layout, and located within 4.6 meters from openings (67\%). An average of $57 \%$ of building occupants in LEED and non-LEED buildings are female, and 53\% of users are included in the age group between 31 and 50 years. In terms of work-related activities, the relative majority of respondents have self-declared their job type as professional $(41 \%)$, have indicated to have spent more than 1 year at their present workspace (68\%), and have stated to occupy their place of work for more than 30 hours per week (78\%). Distributions of responses according to these 'non-environmental' factors are very similar between LEED and non-LEED buildings.

As far as the buildings size is concerned, when the gross area of the buildings of our dataset was compared with the values reported in the CBECS 2003 [30], it was apparent that our database is not representative of the US building stock, due to buildings larger than the reference benchmarks. Based on the bins suggested by CBECS 2003, our dataset was divided in three groups: small buildings, when the gross area was equal or lower than 4,645 $\mathrm{m}^{2}$ (50,000 gsf); medium, between 4,645 $\mathrm{m}^{2}$ and 18,580 $\mathrm{m}^{2}$ (50,000-200,000 gsf); and large, for sizes higher than $18,580 \mathrm{~m}^{2}(200,000 \mathrm{gsf})$. It is evident from Table 5, that there is a strong bias in our dataset towards large buildings (62\% overall, $60 \%$ in LEED buildings and $64 \%$ in non-LEED buildings), as it could be expected considering that the CBE survey has generally been administered upon request from the building owners and/or tenants, who can obtain more reliable information from a web-based survey when having to deal with a large number of occupants. Similar distribution of occupants' responses between LEED and non-LEED buildings can be observed for small and medium-sized buildings.

Finally, to be noted that where the number of individual responses considered for each 'nonenvironmental' factor differs from the total number of occupants' responses available in the dataset $(21,477)$, it means that some of the respondents to the survey did not provide that specific information.

\subsection{Statistical methods}

The mean (M) and median values of satisfaction with different indoor environmental quality parameters and building features were calculated by averaging satisfaction votes of each occupant in the whole dataset.

The statistical significance of differences in mean scores of satisfaction with respect to LEED certification and 'non-environmental' parameters was tested by the Wilcoxon rank sum test (known also as MannWhitney test). Wilcoxon rank sum test is applicable when the variables have an ordinal character [31].

For each statistical influence tested, the power analysis was performed and the effect size index was calculated [32]. While the null-hypothesis significant testing provides information about statistical significance difference, this depends also on the size of the sample used (the bigger, the easier that the difference is significant) and the inability to determine the practical significance of statistical relationship [33,34]. The effect size index shows if the predictor variable has any practical significance. The Spearman rank correlation (Rho) was used to estimate the correlation between categorical variables. Spearman rank correlation was used since the satisfaction votes were measured in ordinal scale [34]. To study the relationships between satisfaction of occupants and LEED certification, individual users' responses were utilized rather than average values for each building. Therefore, 21,477 (number of individual responses) data points were considered and not 144 (number of buildings). In fact, using the building as the statistical unit would have 'artificially' reduced variance and, thus, would have increased the determination and correlation coefficients, implying a loss of information. For example, using only an average value per building would make a building with, say, 20 occupants be as important as a building with 500 occupants. It must be considered that the objective of this study is centered on the satisfaction of the occupants.

Ferguson [34] has proposed conventional benchmarks for what are considered to be 'small', 'medium', and 'large' effects ( $\mathrm{Rho}=0.2,0.5,0.8$, respectively). Rho values lower than 0.2 could be considered as 'negligible'. For all tests, the results were considered statistically significant when $\mathrm{p}<0.05$. The statistical analysis was carried out with R software 2.15.1 [35].

\section{RESULTS}

\subsection{Statistical results of occupant satisfaction}

In Figure 1 (left) are plotted the mean, median, first and third quartile of occupant satisfaction with the building, the workspace, and each of the 15 IEQ parameters of the CBE survey, for both the LEED and the nonLEED groups of buildings. In addition, Figure 1 (center) illustrates the difference between the mean values of satisfaction achieved for each parameter in LEED and non-LEED buildings (LEED minus non-LEED), and also provides (right) the effect size index (Spearman Rho). The plotting order follows a ranking of decreasing overall mean satisfaction scores with the parameters considered in the CBE survey for the chosen dataset (thus, including both LEED and non-LEED buildings), with the exception of satisfaction with the building and satisfaction with the workspace that have been plotted at the top of the chart. 

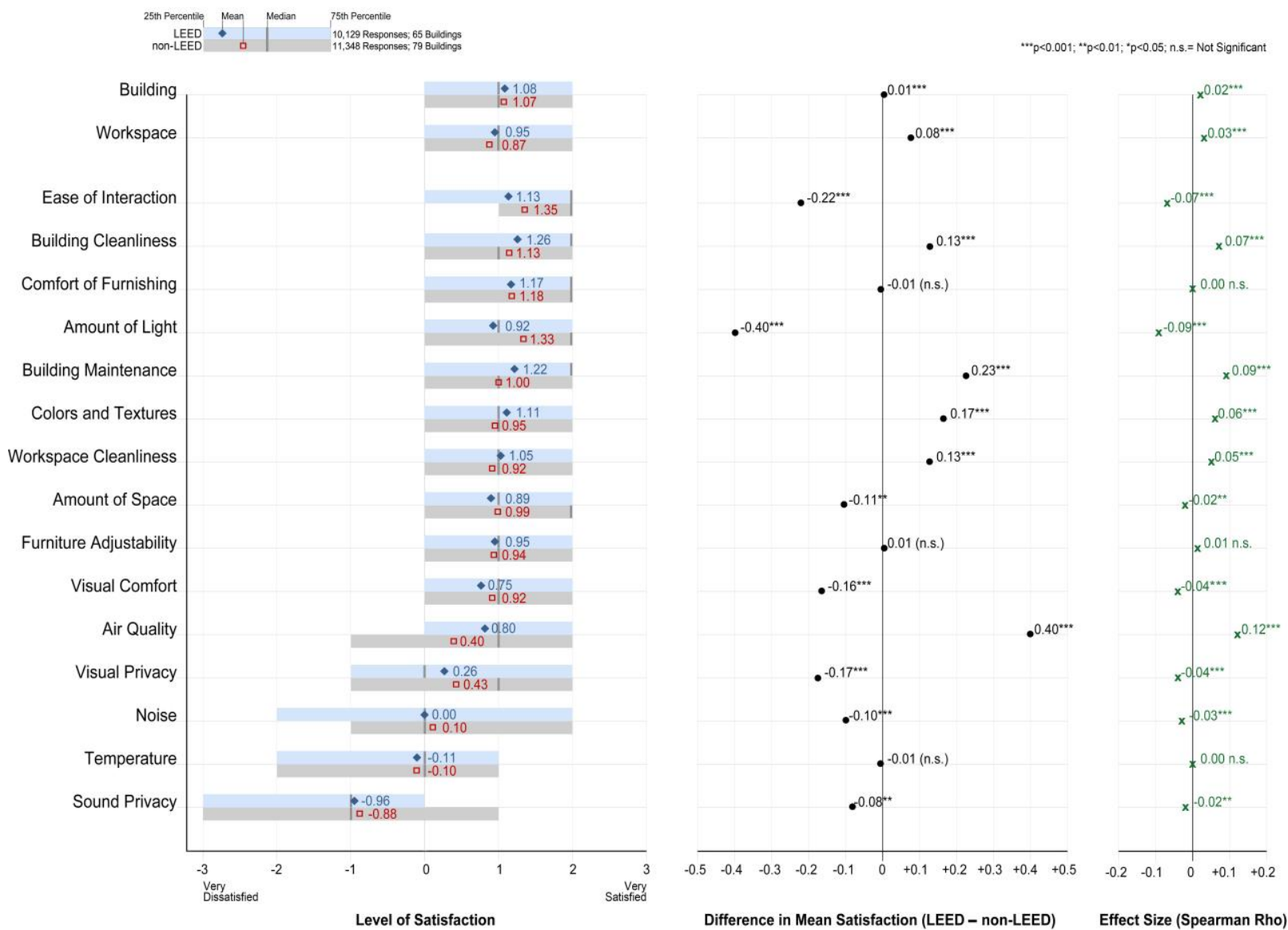

Figure 1 Mean, median, first and third quartile (left); Differences in mean values (LEED - non-LEED) (center); Effect size (Spearman Rho) of occupant satisfaction with the building, the workspace and each of the 15 IEQ parameters for LEED and non-LEED certified buildings (right)

The results indicate that satisfaction scores for both LEED and non-LEED certified buildings present positive mean values - therefore indicating occupant satisfaction with a parameter - for the building overall (LEED: mean $M=1.08$; non-LEED: mean $M=1.07$ ), for the workspace (LEED: $M=0.95$; non-LEED: $M=0.87$ ) and for almost all IEQ parameters considered, with the exception of satisfaction with temperature (LEED: M= 0.11; non-LEED: $\mathrm{M}=-0.10$ ) and sound privacy (LEED: $\mathrm{M}=-0.96$; non-LEED: $\mathrm{M}=-0.88$ ).

In Table 6 below, are reported the mean and standard deviation values for LEED and non-LEED buildings, their relative difference ( $\triangle \mathrm{M}$, LEED minus non-LEED), the p-values, and the effect size (Spearman Rho) for occupant satisfaction with each of the parameters considered. The results reveal that occupants of LEED buildings have equal satisfaction with the building (LEED: $\mathrm{M}=1.08$; non-LEED: $\mathrm{M}=1.07 ; \Delta \mathrm{M}=+0.01, \mathrm{p}<0.001$; effect size $=0.02$ (negligible) ) and the workspace (LEED: $\mathrm{M}=0.95$; non-LEED: $\mathrm{M}=0.87, \Delta \mathrm{M}=+0.08, \mathrm{p}<0.001$; effect size $=0.03$ (negligible)) than occupants of non-LEED buildings. Therefore, it can be stated that LEED rating does not significantly affect occupant satisfaction with the building and with the workspace.

In terms of differences in mean scores of satisfaction with the other 15 IEQ parameters between LEED and non-LEED certified buildings - as per Figure 1 (centre) and Table 6 - LEED buildings have higher mean score of satisfaction with air quality (difference in mean scores between LEED and non-LEED: $\Delta M=+0.40$ ), building maintenance $(\Delta \mathrm{M}=+0.23)$, colors and textures $(\Delta \mathrm{M}=+0.17)$, workspace cleanliness $(\Delta \mathrm{M}=+0.13)$, and building cleanliness $(\Delta \mathrm{M}=+0.13)$. LEED buildings have lower mean scores of satisfaction with amount of light $(\Delta \mathrm{M}=-0.40)$, ease of interaction $(\Delta \mathrm{M}=-0.22)$, visual privacy $(\Delta \mathrm{M}=-0.17)$, visual comfort $(\Delta \mathrm{M}=-0.16)$, amount of space $(\Delta M=-0.11)$, noise $(\Delta M=-0.10)$ and sound privacy $(\Delta M=-0.08)$. No statistically significant differences were found for temperature, furniture adjustability and comfort of furnishing (in these cases, $\mathrm{p}>0.05$ ).

In Table 6 are shown also the effect size indexes calculated using the Spearman correlation coefficient. All parameters have a coefficient Rho smaller than 0.2 , therefore their effect can be considered negligible.

The difference in mean score of satisfaction between LEED and non-LEED buildings with all the parameters investigated (satisfaction with the building overall, with the workspace, and with the 15 IEQ 
parameters) is always lower than 0.40 (in absolute value, $5.7 \%$ relatively to the $-3 \div+3$ scale), and the effect size is always negligible. Therefore, for the data analyzed, it can also be concluded that there is not a significant influence of LEED certification on occupant satisfaction with parameters related to indoor environmental quality.

Table 6 Mean and standard deviation values for LEED and non-LEED buildings, difference, significance and effect size

\begin{tabular}{|c|c|c|c|c|}
\hline Parameter & $\begin{array}{l}\text { LEED } \\
(\text { mean } \pm S D) \\
\end{array}$ & $\begin{array}{l}\text { non-LEED } \\
(\text { mean } \pm S D) \\
\end{array}$ & $\begin{array}{l}\text { Difference } \\
(\Delta \mathrm{M})\end{array}$ & $\begin{array}{l}\text { Effect size } \\
\text { (Spearman Rho) }\end{array}$ \\
\hline Building & $1.08(1.54)$ & $1.07(1.38)$ & $+0.01^{* * *}$ & Negligible $(0.02)^{* * \star}$ \\
\hline Workspace & $0.95(1.53)$ & $0.87(1.53)$ & $+0.08^{* * *}$ & Negligible $(0.03)^{* * *}$ \\
\hline Ease of Interaction & $1.13(1.59)$ & $1.35(1.47)$ & $-0.22^{* * *}$ & Negligible $(-0.07)^{\star * *}$ \\
\hline Building Cleanliness & $1.26(1.55)$ & $1.13(1.42)$ & $+0.13^{\star * *}$ & Negligible $(0.07)^{* * *}$ \\
\hline Comfort of Furnishing & $1.17(1.54)$ & $1.18(1.50)$ & -0.01 n.s. & Negligible $(0.00)$ n.s. \\
\hline Amount of Light & $0.92(1.83)$ & $1.33(1.52)$ & $-0.40^{\star * \star}$ & Negligible $(-0.09)^{\star \star *}$ \\
\hline Building Maintenance & $1.22(1.50)$ & $1.00(1.43)$ & $+0.23^{* * *}$ & Negligible $(0.09)^{\star * *}$ \\
\hline Colors and Textures & $1.11(1.58)$ & $0.95(1.55)$ & $+0.17^{\star * *}$ & Negligible $(0.06)^{\star * *}$ \\
\hline Workspace Cleanliness & $1.05(1.66)$ & $0.92(1.6)$ & $+0.13^{* * *}$ & Negligible $(0.05)^{* * *}$ \\
\hline Amount of Space & $0.89(1.87)$ & $0.99(1.78)$ & $-0.11^{* *}$ & Negligible $(-0.02)^{\star *}$ \\
\hline Furniture Adjustability & $0.95(1.66)$ & $0.94(1.63)$ & +0.01 n.s. & Negligible (0.01) n.s. \\
\hline Visual Comfort & $0.75(1.76)$ & $0.92(1.60)$ & $-0.16^{\star * *}$ & Negligible $(-0.04)^{\star * *}$ \\
\hline Air Quality & $0.80(1.61)$ & $0.40(1.67)$ & $+0.40^{* * *}$ & Negligible $(0.12)^{\star \star \star}$ \\
\hline Visual Privacy & $0.26(1.97)$ & $0.43(1.97)$ & $-0.17^{* * *}$ & Negligible $(-0.04)^{\star * *}$ \\
\hline Noise & $0.00(1.86)$ & $0.10(1.85)$ & $-0.10^{* * *}$ & Negligible $(-0.03)^{* * *}$ \\
\hline Temperature & $-0.11(1.82)$ & $-0.10(1.81)$ & -0.01 n.s. & Negligible $(0.00)$ n.s. \\
\hline Sound privacy & $-0.96(1.89)$ & $-0.88(1.94)$ & $-0.08^{* *}$ & Negligible $(-0.02)^{* *}$ \\
\hline
\end{tabular}

\section{DISCUSSION}

\subsection{Occupant satisfaction with IEQ in office buildings}

This study has analyzed a subset of the CBE Occupant Indoor Environmental Quality Survey database to investigate occupant satisfaction with indoor environmental quality in LEED and non-LEED rated commercial offices, and ultimately ascertain if LEED certified buildings lead to a higher, equal or lower satisfaction with the building, with the workspace, and with each of the 15 IEQ parameters assessed by the CBE survey.

The subset for the study presented in this paper has been based on the dataset utilized by Frontczak et al. [1], who analyzed the CBE database to determine the influence of several parameters of indoor environmental quality and building features on occupant satisfaction. The results obtained in the present study are broadly in line with those achieved by [1], yet with some differences mainly due to the criteria applied for the selection of our specific subset, which features 144 buildings and 21,477 occupants' responses, rather than 350 buildings and 52,980 responses as in Frontczak et al. In fact, in [1] building occupants were found to be generally satisfied with the building overall (mean score of satisfaction: $M=0.84)$ and with the workspace $(M=0.95)$, whilst the highest dissatisfaction was observed for temperature $(M=-0.16)$ and for sound privacy $(M=-0.82)$. The highest satisfaction was achieved for ease of interaction with co-workers $(M=1.30)$, followed by amount of light $(M=$ 1.25). Frontczak et al. [1] concluded in their work that to maximize IEQ satisfaction in commercial offices, satisfaction with the amount of space and storage, with noise level, and with visual privacy, play a primary role.

The results of our study confirm that occupants of buildings in which the CBE survey has been administered are generally satisfied with their space of work, even if slight dissatisfaction is observed particularly with temperature and sound privacy. However, differences with the results of [1] were found in the ranking of some IEQ parameters. In non-LEED buildings, for example, satisfaction with colors and textures $(\mathrm{M}=0.95)$ and with furniture adjustability $(\mathrm{M}=0.94)$ received a higher ranking in our study than in [1], and were characterized by a satisfaction score higher than workspace cleanliness $(M=0.92)$ and visual comfort $(M=0.92)$. It must be considered, however, that the non-LEED group of commercial offices considered in our analysis includes buildings whose year of construction or renovation is, in average, much more recent than those of Frontczak et al.

For LEED certified buildings, the ranking of IEQ parameters is rather dissimilar than that presented in [1], since the highest level of satisfaction expressed by occupants of LEED certified offices in our study is observed with building cleanliness $(M=1.26)$ and building maintenance $(M=1.22)$, followed by comfort of furnishing $(M=1.17)$, ease of interaction $(M=1.13)$, colors and textures, $(M=1.11)$, building overall $(M=1.08)$, workspace cleanliness $(M=1.05)$, furniture adjustability $(M=0.95)$, workspace $(M=0.95)$, amount of light $(M=$ $0.92)$, amount of space $(M=0.89)$, air quality $(M=0.80)$, visual comfort $(M=0.75)$ and visual privacy $(M=0.26)$. 
The parameter of noise level presents a mean score of occupant satisfaction in the LEED group of M=0.00, while - as mentioned - temperature $(M=-0.11)$ and sound privacy $(M=-0.96)$ record a dissatisfaction among occupants.

The findings of our study in terms of mean values of occupant satisfaction with indoor environmental quality in commercial office buildings - both LEED and non-LEED rated - are also broadly consistent with those of other earlier studies on the CBE database (e.g., $[1,21,22,36,37])$, that reported low satisfaction particularly with their thermal and acoustic environment. As previously mentioned - in both LEED and non-LEED certified buildings - the lowest mean score of satisfaction was observed with sound privacy (LEED: M= -0.96; non-LEED: $\mathrm{M}=-0.88$ ). As per the results of further studies on satisfaction with thermal comfort and acoustic privacy in open spaces and private offices [38-42], our analysis therefore confirms that the quality of the thermal and the aural environments are areas of primary concern to provide for the satisfaction of occupants on their workplace.

Further observations about the influence of spatial layouts and office types - as well as other building and workspace characteristic - on variation in occupant satisfaction levels in commercial office buildings, with specific reference to issues of temperature, noise and sound privacy, have been largely discussed in the literature. These studies generally indicate a tendency of a higher satisfaction with IEQ in enclosed offices rather than in open spatial layouts (e.g., [39,41,42]). This trend - also found in [1,29] - has been only partially confirmed by preliminary results of an ongoing research work by the authors on the selected subset of the CBE database. As a matter of fact, it must be considered that, in some cases, occupants may show greater satisfaction and engagement with their tasks in the shared workplace, possibly due to superior arousal and communication with their coworkers [43]. This can have an effect on job satisfaction, work performance and, potentially, productivity [25,44].

\subsection{LEED vs. non-LEED}

In order to correctly frame the results of a comparative evaluation of occupant satisfaction in LEED and non-LEED certified buildings, it should first of all be considered that the USGBC and the LEED rating tool are relatively new to the construction industry, and that the program is currently being characterized by significant investment to further advance the promotion of sustainability in buildings, and the comfort and well-being of its users. Studies such as that presented in this paper have therefore to be considered as an attempt to contribute to improve the standards achieved in buildings certified by the LEED system.

The results of our analysis, as presented in Figure 1 and Table 6, indicate that, based on a statistical evaluation of occupants' responses in LEED and non-LEED buildings selected from the CBE Occupant IEQ Survey database, LEED certification does not significantly affect occupant satisfaction with the building and with the workspace. In addition, the data analyzed in our study lead to conclude that there is not a significant influence of LEED certification on occupant satisfaction with several parameters related to indoor environmental quality.

The conclusions of our study in terms of comparison between occupant satisfaction in LEED and nonLEED certified buildings are considerably different from previous analysis of data extrapolated from the CBE survey database [16-22]. In fact, earlier studies had concluded that LEED rated/green buildings were generally characterized by higher occupant satisfaction with the building, the workspace, air quality, cleaning and maintenance, and thermal comfort. In addition, those results indicated that LEED and green buildings did not perform better in terms of office layout, lighting and acoustics from the point of view of the occupants.

More specifically, previous investigations of data from the CBE database had highlighted a general higher occupants' satisfaction with indoor air quality in LEED buildings. This is in line with the results presented in [17] and then further confirmed by [19-22,45]. In our study - if only differences in mean scores of satisfaction are considered - occupants of LEED buildings are effectively in average more satisfied with the air quality compared to users of non-LEED buildings (difference in mean scores of satisfaction between LEED and nonLEED: $\triangle \mathrm{M}=+0.40)$, but in our analysis this difference has a negligible effect size $(\mathrm{Rho}=0.12)$.

In addition, the study by Abbaszadeh et al. [20], other than emphasizing higher occupant satisfaction with air quality in green buildings, had also indicated a higher satisfaction in LEED buildings with office furnishing, thermal comfort, cleaning and maintenance, the workspace and the building overall. Such conclusions are also consistent with those of Lee and Kim [21] and Lee and Guerin [22]. These results have not been confirmed by our study. In fact, although in our analysis the mean values of satisfaction with building maintenance, building cleanliness, workspace and building overall are in effect slightly higher in LEED buildings (respectively with a difference between LEED and non-LEED buildings of: $\Delta \mathrm{M}=+0.23, \Delta \mathrm{M}=+0.13, \Delta \mathrm{M}=+0.08, \Delta \mathrm{M}=+0.01$ ), the effect size index was negligible for all these IEQ parameters. In addition, no statistical significant difference between LEED and non-LEED buildings was found for satisfaction with comfort of furnishing $(\Delta \mathrm{M}=-0.01)$ and with temperature $(\Delta M=-0.01)$, since in both these cases, $\mathrm{p}>0.05$.

Conversely, in our study, the sole consideration of the mean scores of satisfaction indicates that occupants of LEED buildings tend to be slightly less satisfied with the amount of light compared to non-LEED buildings $(\triangle \mathrm{M}=-0.40)$. This result is broadly in line with the conclusions of Abbaszadeh et al. [20] that had found no improvement in satisfaction with quality of lighting in LEED/green buildings compared with the rest of the CBE 
survey database, even when including in the comparison only buildings constructed in the last 15 years. In our analysis, a lower occupant satisfaction in LEED buildings also applies to the IEQ parameters of ease of interaction $(\Delta \mathrm{M}=-0.22)$, visual comfort $(\Delta \mathrm{M}=-0.16)$ and visual privacy $(\Delta \mathrm{M}=-0.17)$. To be reminded, however, that in our results the effect size is always negligible for all these parameters.

In conclusion, the achievement of considerably different results in our study compared to previous investigations of data from the CBE Occupant Indoor Environmental Quality Survey database is mainly due to:

- A much larger sample size of responses obtained in LEED buildings has been used. Our dataset features 10,129 occupants' responses collected in 65 LEED rated buildings compared to the 16 LEED (plus 9 'green') buildings included in the studies by Huizenga et al. [17,19] and the 15 LEED (plus 6 'green') buildings featured in the work by Abbaszadeh et al. [20], Lee and Kim [21] and Lee and Guerin [22].

- The comparison of occupants' satisfaction in LEED and non-LEED buildings consisted only of responses obtained in buildings comparable in terms of year of construction or renovation, and size.

- Individual occupants' responses (21,477 in total) were considered in the evaluation of the results rather than average values for each of the 144 buildings (LEED and non-LEED) included in our analysis.

- A different statistical approach has been applied; the Wilcoxon rank sum test was utilized to evaluate the statistical significance of differences in mean scores of satisfaction, and the effect size index instead of the null hypothesis testing was used to show if predictor variables have any practical significance.

Finally, to note that the findings of our study are also - at least partially - consistent with the literature review presented by Bird and Newsham in [46], which indicated that, in general, occupants of green buildings tend to show higher satisfaction with air quality and thermal comfort compared to conventional buildings, whereas satisfaction with lighting bears little difference between certified and 'non-green' buildings. On the contrary, their review recognized a clear trend towards a decrease in acoustic satisfaction in green buildings. This could be a potential consequence of credits offered for design strategies (e.g., low or no partitions, hard surfaces, etc.) that allow deeper penetration of daylight and views, and permit to improve air quality. Also, our study supports the conclusions presented by Newsham et al. [27], which highlighted that the LEED rating system might in the future benefit from attention in optimization of visual and thermal comfort, the provision of added control of the internal environment for building occupants, consideration of credits related to acoustic performance and sound reduction, enhanced support for the interdisciplinary design process, and the development of post-occupancy evaluation protocols fully integrated into the accreditation system. The upcoming LEED version $\mathrm{v} 4$ seems to be taking relevant measures to address most (if not all) these issues [15].

\subsection{Limitations and further studies}

As already reported in [1], a limitation in the analysis of the CBE Occupants' Indoor Environmental Quality Survey consists in the fact that the collection of users' responses is not linked with direct appraisal and/or measurement of physical characteristics and IEQ parameters of the building and the workspace. Further to this, in the selection of the buildings featured in the CBE database, no systematic randomized approach has been enforced, and therefore the dataset used for this study cannot be considered as a representative sample of the building stock. It must also be taken into account that other parameters not included in the CBE survey (e.g., the availability of a view out and the layers included in such view, location of the building, etc.) may have a significant influence on occupant satisfaction. In addition, the greatest majority of the responses included in our analysis were obtained from buildings situated in the US (83\%, compared to 7\% of responses from Australia, 5.4\% from Finland, $4.5 \%$ from Canada and $0.4 \%$ from Italy), therefore the results can be said to mainly refer to the North American context.

A further limitation consists in the fact that the sample of buildings included in our analysis is only partially representative of the total amount of buildings rated by LEED to date [11]. In fact, within the occupants' responses of our dataset collected in buildings certified by LEED for New Construction, the 96\% were obtained in offices rated by a version equivalent or earlier than 2.1. These versions have an approximate share of $20 \%$ of the buildings certified by LEED-NC to date. In terms of responses obtained in buildings rated by LEED for Commercial Interiors, $31 \%$ were from offices rated by version 1.0 (corresponding to around $2 \%$ of the spaces rated by LEED-CI), and $69 \%$ from workspaces certified under LEED-CI version 2.0. This version represents the $57 \%$ of all the certifications of LEED for Commercial Interiors. Finally, 10\% of our responses in offices rated by LEED for Existing Buildings were obtained in buildings certified by version 1.0 (equivalent to $1 \%$ of the LEED-EB certifications), $29 \%$ by version 2.0 ( $13 \%$ of the commercial offices rated by LEED-EB) and $61 \%$ by version 2.2 , which represent almost half $(48 \%)$ of the office buildings certified by LEED-EB.

To contextualize this limitation, however, it must be considered that LEED has been following a trend of exponential growth in recent years, both in the US and internationally. In light of this tendency, it is understandable that a study based on the analysis of data collected from a large users' survey in commercial offices may be affected by this continuous evolution of the LEED program, therefore referring to products that may have been already superseded by advances in the rating tool. Nevertheless, it must be noted that, for example, 
in the category of Indoor Environmental Quality in LEED-NC, the distribution of credits has remained largely unchanged between LEED-NC version 2.1, 2.2 and 2009, although clearly the requirements for the award of each credit have increasingly been specified, and have progressively become more difficult to achieve.

To properly interpret our results, it may also be considered that in the latest "Green Building Market and Impact Report 2011", Watson [5] stated that in recent years "there has been a general move away from indoor environmental quality (IEQ) measures in LEED certified projects compared to previous versions of the standard [LEED v2009]. It could be very well that this is due to a combination of increased credit requirements and decreased credit available for IEQ measures". Also, [5] reported that in the development process of LEED v2009, an excessive emphasis may have been given to energy-related credits, to the detriment of the materials and the indoor environment categories. As a consequence, although our dataset can represent only partially the current market penetration of the LEED program, the results obtained may be considered significant to reflect on the existing conditions in commercial office buildings, and better suggest avenues of development - as well as areas of concern - to be addressed by future versions of the LEED system.

It is also important to note that this study did not consider the potential influence of the variation of 'nonenvironmental' factors on occupant satisfaction in LEED and non-LEED certified buildings. Analysis of such relationships will be part of a further study by the authors. In addition, future studies will need to investigate the possible correlation existing between satisfaction of occupants, LEED certification level (platinum, gold, silver, certified), LEED product under which buildings have been rated (e.g., New Construction, Existing Buildings and Commercial Interiors), and their different versions (and therefore the credit allocation within such products). Finally, an investigation of the individual scorecards of the buildings featured in the chosen dataset of the CBE survey database will also be necessary, so as to ascertain the credit distribution under the IEQ category that each building has achieved, and correlate this with the votes of satisfaction expressed by occupants with the various parameters influencing the indoor environmental quality of their workspace.

\section{CONCLUSIONS}

The main conclusions that can be drawn from the analysis presented in this paper include the following:

- Occupants of LEED certified buildings have equal satisfaction with the building overall (LEED: M=1.08; non-LEED: $\mathrm{M}=1.07 ; \Delta \mathrm{M}=+0.01, \mathrm{p}<0.001$; effect size $=0.02$ (negligible)) and with the workspace (LEED: $\mathrm{M}=0.95$; non-LEED: $\mathrm{M}=0.87, \Delta \mathrm{M}=+0.08, \mathrm{p}<0.001$; effect size $=0.03$ (negligible)) than occupants of nonLEED buildings. Therefore, LEED rating does not significantly affect building and workspace satisfaction.

- The analysis of the mean votes of satisfaction indicates that occupants of LEED buildings tend to be slightly more satisfied with the air quality $(\Delta \mathrm{M}=+0.40 ; \mathrm{p}<0.001$, effect size $=0.12$ (negligible) $)$, building maintenance $(\Delta \mathrm{M}=+0.23 ; \mathrm{p}<0.001$; effect size $=0.09$ (negligible $))$, colors and textures $(\Delta \mathrm{M}=+0.17$; $\mathrm{p}<0.001$; effect size $=0.06$ (negligible) $)$, building cleanliness $(\Delta \mathrm{M}=+0.13 ; \mathrm{p}<0.001 ;$ effect size $=0.07$ (negligible)), and workspace cleanliness $(\Delta \mathrm{M}=+0.13 ; \mathrm{p}<0.001$; effect size $=0.05$ (negligible) $)$ than occupants of non-LEED buildings. These relationships are all statistically significant $(\mathrm{p}<0.05)$, but they present a negligible effect size $($ Rho $<0.20)$.

- Consideration of mean satisfaction scores suggests that, on average, occupants of LEED certified buildings have the tendency to be slightly less satisfied with the amount of light $(\Delta \mathrm{M}=-0.40 ; \mathrm{p}<0.001$; effect size $=$ 0.09 (negligible)), ease of interaction $(\Delta \mathrm{M}=-0.22 ; \mathrm{p}<0.001$; effect size $=-0.07$ (negligible) $)$, visual privacy $(\Delta \mathrm{M}=-0.17 ; \mathrm{p}<0.001 ;$ effect size $=-0.04$ (negligible $)$ ), visual comfort $(\Delta \mathrm{M}=-0.16 ; \mathrm{p}<0.001$; effect size $=-$ 0.04 (negligible)), and amount of space $(\Delta \mathrm{M}=-0.11 ; \mathrm{p}<0.001$; effect size $=-0.02$ (negligible) $)$ than occupants of non-LEED buildings. Also in this case, all the outcomes of the analysis have significant statistical value $(\mathrm{p}<0.05)$, but have a negligible effect size $($ Rho $<0.20)$.

- No statistical significance was found for differences in occupant satisfaction with furniture adjustability, temperature, and comfort of furnishing in both LEED and non-LEED certified buildings ( $\mathrm{p}>0.05$ ).

- The results obtained differ from previous studies conducted on data from the CBE Occupant Indoor Environmental Quality Survey database since: the selection of the dataset, the sample size, and the statistical tests applied were different; LEED buildings were compared to non-LEED building of similar age and size; and, individual responses rather than building average values were considered.

\section{ACKNOWLEDGMENTS}

This paper is part of the research activities developed by the first author at the Center for the Built Environment (CBE), University of California Berkeley (USA), funded by the HEA-Higher Education Academy (United Kingdom), International Scholarship Scheme. The authors would like to thank Gail Brager, Ed Arens and John Goins for their valuables advices, and Monika Frontczak for the development of the dataset in R. 


\section{REFERENCES}

[1] Frontczak M, Schiavon S, Goins J, Arens EA, Zhang H, Wargocki P. Quantitative relationships between occupant satisfaction and satisfaction aspects of indoor environmental quality and building design. Indoor Air 2012;22:119-31.

[2] Veitch JA, Charles KE, Farley KMJ, Newsham GR. A model of satisfaction with open-plan office conditions: COPE field findings. J Environ Psychol 2007;27:177-89.

[3] Van Dick R, Christ O, Stellmacher J, Wagner U, Ahlswede O, Grubba C et al. Should I stay or should I go? Explaining turnover intentions with organizational identification and job satisfaction. Br J Manage 2004; 15:351-60.

[4] U.S. Green Building Council. What LEED is. 2011;2012.

[5] Watson R. Green Building Impact Report. 2008.

[6] Heerwagen JH. Green buildings, organizational success and occupant productivity. Build Res Inf 2000;28:35367.

[7] Loftness V, Lam KP, Hartkopf V. Education and environmental performance-based design: a Carnegie Mellon perspective. Building Research \& Information 2005;33:196-203.

[8] Newsham GR, Mancini S, Birt BJ. Do LEED-certified buildings save energy? Yes, but... Energy and Buildings 2009;41:897-905.

[9] Scofield JH. Do LEED-certified buildings save energy? Not really... Energy and Buildings 2009;41:1386-90.

[10] U.S. Green Building Council. Foundations of LEED. 2009;2012.

[11] U.S. Green Building Council. LEED - Leadership in Energy and Environmental Design. 2012;2012.

[12] U.S. Green Building Council. LEED - New Construction and Major Renovations. 2012;2012.

[13] U.S. Green Building Council. LEED - Existing Buildings. 2012;2012.

[14] U.S. Green Building Council. LEED for Commercial Interiors. 2012;2012.

[15] U.S. Green Building Council. LEED v4 - The Next Version of LEED. 2013;2013.

[16] Zagreus L, Huizenga C, Arens EA, Lehrer D. Listening to the occupants: a Web-based indoor environmental quality survey. Indoor Air 2004;14 (Suppl. 8):65-74.

[17] Huizenga C, Zagreus L, Arens EA, Lehrer D. Measuring Indor Environmental Quality: A Web-based Indoor Occupant Satisfaction Survey. Proceedings of Greenbuild Conference, Pittsburgh 2003.

[18] Huizenga C, Laeser K, Arens EA. A Web-Based Occupant Satisfaction Survey for Benchmarking Building Quality. Proceedings of Indoor Air, Monterey, CA 2002.

[19] Huizenga C, Zagreus L, Abbaszadeh S, Lehrer D, Goins J, Hoe L et al. LEED Post-Occupancy Evaluation: Taking Responsibility for the Occupants. Proceedings of Greenbuild Conference 2005.

[20] Abbaszadeh S, Zagreus L, Lehrer D, Huizenga C. Occupant Satisfaction with Indoor Environmental Quality in Green Buildings. Proceedings of Healthy Buildings 2006;III:365-70.

[21] Lee YS, Kim S. Indoor Environmental Quality in LEED-Certified Buildings in the US. Journal of Asian Architecture and Building Engineering 2008;7:293-300.

[22] Lee YS, Guerin DA. Indoor Environmental Quality Related to Occupant Satisfaction and Performance in LEED-certified Buildings. Indoor and Built Environment 2009;18:293-300.

[23] Baird G, Leaman A, Thompson J. A comparison of the performance of sustainable buildings with conventional buildings from the point of view of the users. Architectural Science Review 2012;55:135-44.

[24] Singh A, Syal M, Grady SC, Korkmaz S. Effects of Green Buildings on Employee Health and Productivity. American Journal of Public Health 2010;100:1665-8.

[25] Leaman AJ, Thomas L, Vandenberg M. 'Green buildings: What Australian building users are saying. EcoLibrium 2007:22-30.

[26] Leaman AJ, Bordass WT. Are users more tolerant of 'green' buildings? Building Research and Information 2007;35:662-73.

[27] Newsham G, Birt B, Arsenault C, Thompson L, Veitch J, Mancini S et al. Do Green Buildings Outperform Conventional Buildings? Indoor Environment and Energy Performance in North American Offices. National Research Council Canada 2012;RR-329:1-71.

[28] U.S. Green Building Council. LEED Certified Project Directory. 2011;2012.

[29] Frontczak M, Wargocki P. Literature survey on how different factors influence human comfort in indoor environments. Building and Environment 2011;46:922-37.

[30] U.S. Energy Information Administration. Commercial Buildings Energy Consumption Survey (CBECS). 2003;2012.

[31] Siegel S. Nonparametric statistics for the behavioral sciences. 1956.

[32] Cohen J. Statistical power analysis for the behavioral sciences. : Lawrence Erlbaum, 1988.

[33] Cohen J. A power primer. Psychol Bull 1992;112:155. 
[34] Ferguson CJ. An effect size primer: A guide for clinicians and researchers. Professional Psychology: Research and Practice 2009;40:532.

[35] R Development Core Team. R: A language and environment for statistical computing. 2011; R version 2.13.1.

[36] Huizenga C, Abbaszadeh S, Zagreus L, Arens EA. Air quality and thermal comfort in office buildings: results of a large indoor environmental quality survey. Proceedings of Healthy Buildings 2006;III:393-7.

[37] Jensen KL, Arens EA, Zagreus L. Acoustical quality in office workstations, as assessed by occupant surveys. Proceedings of Indoor Air 2005:2401-5.

[38] Marans RW, Yan X. Lighting quality and environmental satisfaction in open and enclosed offices. Journal of Architectural and Planning Research 1989;6:118-31.

[39] Lee YS, Guerin DA. Indoor environmental quality differences between office types in LEED-certified buildings in the US. Building and Environment 2010;45:1104-12.

[40] Lee YS. Office layout affecting privacy, interaction, and acoustic quality in LEED-certified buildings. Building and Environment 2010;45:1594-600.

[41] Veitch JA, Farley KMJ, Newsham GR. Environmental satisfaction in open-plan environments: 1 . Scale validation and methods. 2002;IRC-RR-844.

[42] Veitch JA, Charles KE, Newsham GR, Marquardt CJG, Geerts J. Environmental satisfaction in open-plan environments: 5. Workstation and physical condition effects. 2003;IRC-RR-154,.

[43] Heerwagen JH, Kampschroer K, Powell KM, Loftness V. Collaborative knowledge work environment. Building Research \& Information 2004;32:510-28.

[44] Leaman AJ, Bordass WT. Assessing building performance in use 4: the Probe occupant surveys and their implications. Building Research and Information 2001;29:129-43.

[45] Brager GS, Baker L. Occupant Satisfaction in Mixed-Mode Buildings. Proceedings of Air Conditioning and the Low Carbon Cooling Challenge Windsor, UK 2008.

[46] Birt B, Newsham GR. Post-occupancy evaluation of energy and indoor environment quality in green buildings: a review. 3rd International Conference on Smart and Sustainable Built Environments 2009:1-7. 